\title{
GMR
}

\section{Differential expression of Toll-like receptors in goat dominant and nondominant follicles}

\author{
G.X. E ${ }^{1 *}$, Y.J. Zhao ${ }^{1 *}$, Y.H. $\mathrm{Ma}^{2}$, M.X. $\mathrm{Chu}^{2}$, Q.H. Hong ${ }^{3}$, S.J. $\mathbf{L v}^{4}$, \\ L. Zhu ${ }^{3}$, F.K. Li ${ }^{4}$, Y.G. Han ${ }^{1}$, X. Wu ${ }^{5}$ and Y.F. Huang ${ }^{1}$ \\ ${ }^{1}$ College of Animal Science and Technology, \\ Chongqing Key Laboratory of Forage \& Herbivore, \\ Chongqing Engineering Research Centre for Herbivores Resource Protection \\ and Utilization, Southwest University, Chongqing, China \\ ${ }^{2}$ Institute of Animal Science, Chinese Academy of Agricultural Sciences, \\ Beijing, China \\ ${ }^{3}$ Yunnna Animal Scinence and Veterinary Institute, Kunming, China \\ ${ }^{4}$ College of Life Sciences, Linyi University, Linyi, Shandong, China \\ ${ }^{5}$ Faculty of Veterinary Medicine, Khon Kaen University, Khon Kaen, Thailand \\ *These authors contributed equally to this study. \\ Corresponding author: Y.F. Huang \\ E-mail: H67738337@swu.edu.cn
}

Genet. Mol. Res. 15 (4): gmr15049157

Received October 5, 2016

Accepted November 11, 2016

Published December 19, 2016

DOI http://dx.doi.org/10.4238/gmr15049157

Copyright (C) 2016 The Authors. This is an open-access article distributed under the terms of the Creative Commons Attribution ShareAlike (CC BY-SA) 4.0 License.

\begin{abstract}
The mechanism of dominant follicle selection is unclear because of its physiological complexity. However, some studies have reported that the immune system plays an important role in reproductive physiology. The objective of the current study was to investigate the differential expression of Toll-like receptors (TLRS) in the dominant (DFs) and nondominant follicles (NFs), and to determine the correlation between the expression of TLRS and the related genes, such as WNT4 and FOXL2. In this comparative study, the expression
\end{abstract}


levels of TLRs, WNT4, and FOXL2 genes of DFs and NFs were obtained from three Dazu black goats were estimated using the real-time PCR. Our results showed no significant difference in the expression of seven TLRs (excluding TLR2, TLR5, and TLR8), WNT4, and FOXL2 between the DFs and NFs. In addition, the mRNA expression levels of WNT4 significantly correlated with the relative expression of TLR6 $(r$ $=0.949739, \mathrm{P}<0.01)$; however, no significant expression of the $T L R$ genes was found to be associated with FOXL2 mRNA expression. Our results support the fact that TLRS are not involved in the process of dominant follicle selection; however, TLR6 might play a role in the development of follicles by interacting with WNT4.

Key words: Toll-like receptors; Goat; Fecundity; WNT4; FOXL2; Dominant follicle selection

\section{INTRODUCTION}

Toll-like receptors (TLRs) play an important role in pathogen recognition through the broadly specific innate immune system (Brubaker et al., 2015). In addition, their functional mechanism in immune system mainly depends on some specific genes such as $M y D 88, C D 40$, and $N F-k B$ (Raja et al., 2011). A previous study has reported the presence of ten family members of TLRs in several mammals, including goat (Raja et al., 2011). However, to date, the TLRs have been thought not only to be the key mediators of the innate immune system, but also important players in the female reproduction, and their expression levels vary in different phases of the menstrual cycle (Aflatoonian et al., 2007; Aflatoonian and Fazeli, 2008; Zandieh et al., 2016).

Mammalian follicular development is a complex process, including the recruitment of the primitive follicles, development of preantral follicles, and selection, growth and maturation of antral follicle or follicle atresia. Follicle selection is a key step to determine the number of ovulated oocytes, and oocyte growth is an important index for dominant follicle selection. Some studies have reported the absence of immune cells (Bromfield and Sheldon, 2011) as well as some TLR genes, such as TLR4 (Hoshino et al., 1999), in the ovarian follicles. However, ovulation itself is regarded as a sterile inflammatory process involving the innate immune system (Spanel-Borowski, 2011) and some TLRs, such as TLR2 and TLR4, play a role in sperm capacitation and oocyte fertilization (Shimada et al., 2008). Until now, the mechanism of follicle selection is unclear due to its physiological complexity, and it is also not clear whether the TLRs could impact this process during follicle development.

Furthermore, the ovarian development requires the female-specific functions mediated by the WNT4 (wingless-related MMTV integration site 4), and FOXL2 (forkhead box L2) proteins, which establish fetal granulosa cells and regulate folliculogenesis (Tomizuka et al., 2008; Hirano et al., 2016). Another study attributed the putative mechanism of FOXL2mediated ovarian development to the regulation of ER $\beta$-dependent gene expression in the earlyphase follicular development (Hirano et al., 2016). In addition, WNT4 repression leads to the premature activation of follicles prior to formation of testis-like cords (Maatouk et al., 2013). Therefore, these two genes, WNT4, and FOXL2, play an important role in the development of the follicle. Thus, it is critical to understand the mechanism of follicle selection by studying the involvement and regulation of TLRs, WNT4, and FOXL2 in goat follicular selection.

Genetics and Molecular Research 15 (4): gmr15049157 


\section{MATERIAL AND METHODS}

\section{Animals}

Experimental procedures used in this study were approved by the Committee on the Ethics of Animal Experiments of the Southwest University [No. (2007) 3] and the Animal Protection Law of China. Ovaries of three 1-1.2-year-old Dazu black goats were collected at Southwest University in China. Their follicles were stripped from ovaries in $37^{\circ} \mathrm{C}$ saline immediately after removal. The follicles of 3 female individuals were divided into dominant (diameter $>5 \mathrm{~mm}$ ) and nondominant follicles $(3 \mathrm{~mm}<$ diameter $<5 \mathrm{~mm}$ ) using the standard protocol (Medan et al., 2005).

\section{Methods and data analysis}

Total cellular RNA was extracted from the isolated follicles using the TRIzol reagent (Invitrogen, Carlsbad, CA, USA) per manufacturer's protocol. The RNA quality was determined using a 2100 Bioanalyzer (Agilent Technologies, Santa Clara, CA, USA). The cDNA was synthesized by using a High-Capacity cDNA Reverse Transcription Kit (Applied Biosystems, Foster City, CA, USA). The samples used in the quantitative real-time PCR (Q-PCR) analyses were the same as those used in the sequencing experiments. The primers of the candidate genes are shown in Table 1. The Q-PCR was performed in triplicate in a $20-\mu \mathrm{L}$ reaction volume comprising $10 \mu \mathrm{L} 2 \mathrm{X}$ SYBR ${ }^{\circledR}$ Select Master Mix (Life Technologies, Carslbad, CA, USA), 6.4 $\mu \mathrm{L} \mathrm{H}_{2} \mathrm{O}, 0.8 \mu \mathrm{L}$ each forward and reverse primer $(10 \mathrm{pmol} / \mu \mathrm{L})$, and $2 \mu \mathrm{L} \mathrm{cDNA}(\sim 16 \mathrm{ng})$. The reaction was performed using the StepOnePlus ${ }^{\mathrm{TM}}$ Real-Time PCR System (Applied Biosystems). The cycle threshold $(\mathrm{Ct})$ values were normalized to the control gene (GAPDH). The relative quantification was calculated using the $2^{-\Delta \Delta \mathrm{Ct}}$ method (Schmittgen and Livak, 2008).

Each experiment was independently repeated three times, and each sample was evaluated in triplicate. Using the $t$-test in the SPSS18 software, a P value less than 0.05 was considered significant. The assessment of genes was correlated using $r$, with the following statistical formula:

$$
r=\frac{\sum_{i=1}^{n}\left(x_{i}-\bar{x}\right)\left(y_{i}-\bar{y}\right)}{\sqrt{\sum_{i=1}^{n}\left(x_{i}-\bar{x}\right)^{2} \sum_{i=1}^{n}\left(y_{i}-\bar{y}\right)^{2}}}
$$

where $x_{i}$ and $y_{i}$ are the corresponding values of the data of two groups, respectively, and the $\bar{x}$ and $\bar{y}$ are the mean values of the data of two groups. The correlation coefficient $(r)$ was calculated to determine the correlation between the two variables and their relative directions.

\section{RESULTS}

The quality of Q-PCR was determined by agarose gel electrophoresis as shown in Figure 1. A high PCR-effect and appropriate fragment length of the amplicon of each candidate gene, except TLR2,TLR5, and TLR8, were observed on the agarose gel. Therefore, we excluded these three genes from our study. The relative mRNA expression of the TLR genes, measured by Q-PCR, are shown in Figure 2. The results showed no significant difference in the relative mRNA expression of TLRs, WNT4, and FOXL2 between dominant and nondominant follicles.

Genetics and Molecular Research 15 (4): gmr15049157 
Table 1. Information of Q-PCR primer.

\begin{tabular}{|c|c|c|c|c|}
\hline Candidate genes & Primer & Primer sequences & SZ or RF & $\operatorname{Tm}\left({ }^{\circ} \mathrm{C}\right)$ \\
\hline \multirow[t]{2}{*}{ FOXL2 } & FOXL2-F & CCGGCATCTACCAGTACATTATAGC & \multirow[t]{2}{*}{ Boulanger et al. (2014) } & \multirow[t]{2}{*}{60} \\
\hline & FOXL2-R & GCACTCGTTGAGGCTGAGGT & & \\
\hline \multirow[t]{2}{*}{ WNT4 } & WNT4-F & CTCCCTCACGAAGACAAGGT & \multirow[t]{2}{*}{151} & \multirow[t]{2}{*}{60} \\
\hline & WNT4-R & CATCCACATCAGAGCTTGCC & & \\
\hline \multirow[t]{2}{*}{ TLRI } & TLR1-F & CTG CCCATATGCCAAGAG TT & \multirow[t]{2}{*}{159} & \multirow[t]{2}{*}{60} \\
\hline & TLR1-R & GGCATCTTCTCTTTCCCCAT & & \\
\hline \multirow[t]{2}{*}{$\overline{T L R 2}$} & TLR2-F & CTGTGTGCGTCTTCCTCAGA & \multirow[t]{2}{*}{228} & \multirow[t]{2}{*}{62} \\
\hline & TLR2-R & TCAGGGAGCAGAGTAACCAGA & & \\
\hline \multirow[t]{2}{*}{$\overline{T L R 3}$} & TLR3-F & TCTTTTCGGGACTGTTGA CC & \multirow[t]{2}{*}{224} & \multirow[t]{2}{*}{62} \\
\hline & TLR3-R & AAATCCCCCATCCAAGGTAG & & \\
\hline \multirow[t]{2}{*}{ TLR4 } & TLR4-F & GGTTTCCACAAAAGCCGTAA & \multirow[t]{2}{*}{137} & \multirow[t]{2}{*}{62} \\
\hline & TLR4-R & AGGACGATGAAGATGATGCC & & \\
\hline \multirow[t]{2}{*}{$\overline{T L R 5}$} & TLR5-F & TCAATGGGA GCCAGATTTTC & \multirow[t]{2}{*}{198} & \multirow[t]{2}{*}{62} \\
\hline & TLR5-R & CCTTCAGCTCCTGGAGTGTC & & \\
\hline \multirow[t]{2}{*}{ TLR6 } & TLR6-F & CGACATTGAAGGCACTGAAA & \multirow[t]{2}{*}{148} & \multirow[t]{2}{*}{62} \\
\hline & TLR6-R & TCCTGAGGACAAAGCATGTG & & \\
\hline \multirow[t]{2}{*}{ TLR7 } & TLR7-F & TCTCCAAGGTGCTTTCCAGT & \multirow[t]{2}{*}{166} & \multirow[t]{2}{*}{62} \\
\hline & TLR7-R & CCACCAGACAAACCACACAG & & \\
\hline \multirow[t]{2}{*}{$\overline{T L R 8}$} & TLR8-F & TCACACGGGTAACGAATGAA & \multirow[t]{2}{*}{143} & \multirow[t]{2}{*}{62} \\
\hline & TLR8-R & TTTGAGGTTGAGAAATGCCC & & \\
\hline \multirow[t]{2}{*}{ TLR9 } & TLR9-F & CTCTCCTTGGACTGCTTTGG & \multirow[t]{2}{*}{204} & \multirow[t]{2}{*}{62} \\
\hline & TLR9-R & CACTGCACTCTGCACCTTGT & & \\
\hline$\overline{T L R 10}$ & TLR10-F & TCACCTGACATCTTTGCGAG & 187 & 60 \\
\hline & TLR10-R & TCGGAATGGATTTCTTCCTG & & \\
\hline$\overline{G A P D H}$ & GAPDH-F & CGACTTCAACAGCGACACTCAC & 119 & 60 \\
\hline & GAPDH-R & CCCTGTTGCTGTAGCCGAATTC & & \\
\hline
\end{tabular}

$\mathrm{SZ}$ is the size (bp) of candidate gene; RF is the reference for the primer pair; $\mathrm{F}$ is the forward primer; and $\mathrm{R}$ is the reverse primer.

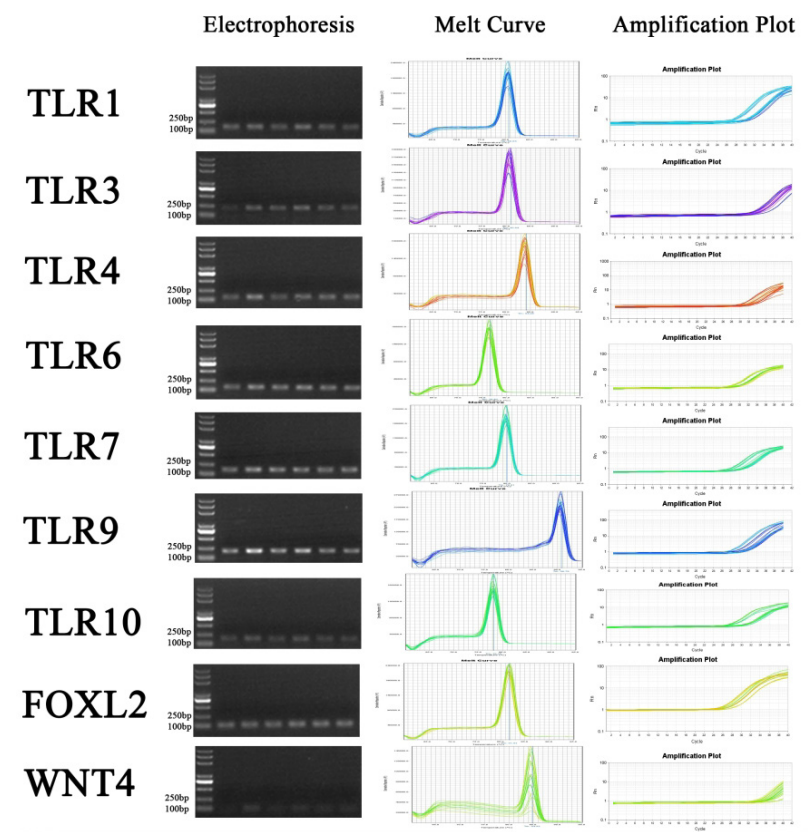

Figure 1. Relative mRNA expression patterns of TLRs, WNT4, and FOXL2 in dominant and nondominant follicles in goat using Q-PCR.

Genetics and Molecular Research 15 (4): gmr15049157 

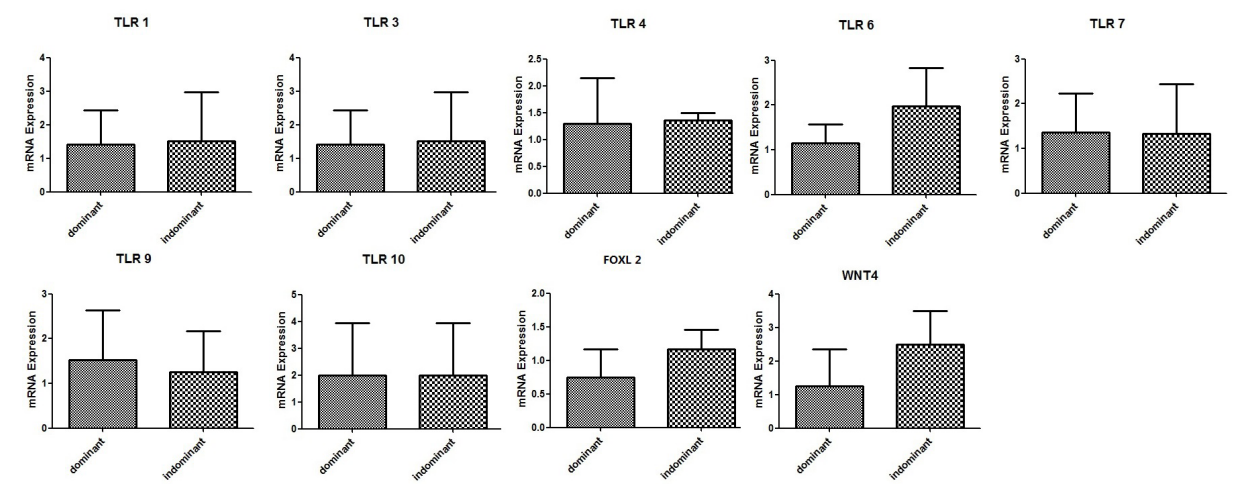

Figure 2. Real-time Q-PCR validation of the expression of TLRs, WNT4, and FOXL2 in dominant and nondominant goat follicles. The abundance of target genes was normalized relative to the abundance of the GAPDH gene. Bars in each panel represent the mean \pm standard error (sample number $=3$, and 3 parallel repetitions per sample).

Correlation between mRNA expressions of the TLR genes with those of the WNT4 and FOXL2 genes are shown in Table 2. Among TLRs, a non-significant negative correlation was observed between TLR3 and TLR7 $(r=-0.00375)$, between TLR3 and TLR9 $(r=-0.03518)$. The relative mRNA expression level of the TLR1 gene was significantly correlated with those of TLR7 $(r=0.992134, \mathrm{P}<0.01)$ and TLR9 $(r=0.931833, \mathrm{P}=0.01)$. The relative mRNA expression level of TLR10 was positively associated with those of TLR1 $(r=0.976384$, P $<0.01)$, TLR7 $(r=0.990495, \mathrm{P}<0.01)$, and TLR9 $(r=0.981517, \mathrm{P}<0.01)$. In addition, the relative mRNA expression level of TLR7 was positively associated with that of TLR9 ( $r$ $=0.964066, \mathrm{P}<0.01)$. The correlation analysis between the relative mRNA expression of TLR genes and WNT4 and FOXL2 genes showed that the high levels of the relative mRNA expression of the WNT4 gene were correlated with those of the FOXL2 $(r=0.885591, \mathrm{P}=$ $0.02)$ and TLR6 $(r=0.949739, \mathrm{P}<0.01)$. However, the mRNA expression of no TLR gene was significantly associated with that of the FOXL2 gene.

Table 2. Correlation analysis between TLRs and WNT4 and FOXL2.

\begin{tabular}{l|c|c|c|c|c|c|c|c|c}
\hline & FoxL2 & TLR10 & TLR1 & TLR3 & TLR4 & TLR6 & TLR7 & TLR9 & WNT4 \\
\hline FOXL2 & 1 & & & & & & & \\
\hline TLR10 & +0.491528 & 1 & & & & & & \\
\hline TLR1 & +0.51741 & $+0.976384^{* *}$ & 1 & & & & & \\
\hline TLR3 & +0.164768 & +0.046931 & -0.02672 & 1 & & & & \\
\hline TLR4 & +0.489107 & +0.638114 & +0.504745 & +0.009249 & 1 & & & \\
\hline TLR6 & +0.830143 & +0.635346 & +0.630347 & +0.597080 & +0.410306 & 1 & & \\
\hline TLR7 & +0.505915 & $+0.990495^{* *}$ & $+0.992134^{* *}$ & -0.00375 & +0.548934 & +0.630456 & 1 & \\
\hline TLR9 & +0.411253 & $+0.981517^{* *}$ & $+0.931833^{* *}$ & -0.03518 & +0.691826 & +0.527048 & $+0.964066^{* *}$ & 1 & \\
\hline WNT4 & $+0.885591^{*}$ & +0.701023 & +0.671865 & +0.440016 & +0.650055 & $+0.949739^{*}$ & +0.6731 & +0.617487 & 1 \\
\hline
\end{tabular}

The absolute value of the correlation coefficient closer to 1 indicates greater correlation, and the value closer to 0 indicates lower correlation; "+" indicates positive correlation between genes, and "-" indicates negative correlation. $* \mathrm{P}<0.05$, and $* * \mathrm{P}<0.01$ using the $t$-test.

\section{DISCUSSION}

Consistent with the recent reports of TLR expression in humans, high levels of the mRNA expression of TLR1, TLR3, TLR4, TLR6, TLR7, TLR9, and TLR10 genes were found 
in follicles (Taghavi et al., 2014). Furthermore, this finding is in agreement with the study of Bromfield and Sheldon (2011), which showed that the TLRs involved in the development of other female reproductive tissues, such as bovine granulosa cells, initiate an innate immune response to lipopolysaccharide (LPS) via the TLR4 pathway, leading to the inflammation and perturbation of meiotic competence. The expressions of TLR2 and TLR4 genes were upregulated in response to LPS in the uterine horn and uterine body, as well as TLR4 expressed in the ovary of rabbit (Chen et al., 2014). The abnormal expression of TLRs might adversely affect the oocyte quality and fertility rate, and it might also lead to the lower embryo quality in women with polycystic ovary syndrome (PCOS) (Gu et al., 2016). However, in this study, no significant differences in mRNA expression of the TLR genes were observed between the dominant (DFs) and nondominant follicles (NFs). To date, differential expression of the TLRs related to the dominant follicular selection process has not been reported in vertebrates. On one hand, our results suggest that the TLRs do not play a key role in this biological process. On the other hand, the widespread expression of TLRs in different developmental stages of follicles was consistent with the fact that the autoimmune system plays a critical role in the reproductive functioning in both males and females (Sominsky et al., 2013).

Originally, the FOXL2 gene was considered to play a role in the sex determination and generation of sex-reversal phenotype in goat (Auguste et al., 2011; Boulanger et al., 2014). In addition, previous studies have shown that a somatic missense mutation in the FOXL2 gene, which is expressed in the ovary, have a high correlation to granulosa cell tumors (Schmidt et al., 2004; Gustin et al., 2016). The FOXL2 mutant has also been found to affect the hormone production, apoptosis, and proliferation in vitro (Leung et al., 2016). However, more evidence is required to support the fact that FOXL2 is involved in some pathway related to the regulation of follicle development (Georges et al., 2013; Jin et al., 2016). Here, the high mRNA expression levels of the TLR genes in the DFs and NFs are consistent with the above findings. Furthermore, no significant difference in the expression of TLR genes was observed between these two developmental stages of follicles, and the correlation between TLRs and FOXL2 indicated no interaction between them to regulate the process of dominant follicular selection.

Previous studies have demonstrated that the WNT4 gene was expressed in the ovary and is involved in gonadal development (Meng et al., 2015). It is an irreplaceable signal gene for the development of the ovary; the expression of a WNT4 knock-out gene in gonads led to the sexually dimorphic functions (Naillat et al., 2015). Thus, owing to the high levels of WNT4 mRNA expression in the DFs and NFs, and no significant difference between the follicles of the two groups, WNT4 could be considered an important factor involved in follicular cell development (Wu et al., 2015), but not in the process of dominant follicle selection.

According to the classification based on the cellular location of TLRs, the TLR6 is located within the cell membrane (Taghavi et al., 2014). At the same time, high levels of the TLR6 mRNA expression have been found on the surface epithelium of human ovaries (Zhou et al., 2009). Besides, the TLR6 gene expression was significantly higher in patients with poor ovarian response in comparison to the normal women (Taghavi et al., 2014). Interestingly, the mRNA expression levels of TLR6 positively associated with those of the WNT4 gene. It could be inferred that the interaction between TLR6 and WNT4 proteins is involved in the normal physiological development of follicles.

The aim of this study was to discover the differential expression of the TLRs in the DFs and NFs, and to investigate the correlation between TLRs and WNT4 and FOXL2 using Q-PCR. Our results showed no significant difference in the relative expression of TLRs, 
WNT4, and FOXL2 between the DFs and NFs, indicating that the TLRs were not involved in the dominant selection process. In addition, a significant correlation was observed in the relative mRNA expression levels of WNT4 and TLR6 $(r=0.949739, \mathrm{P}<0.01)$, indicating that TLR6 might play a role in the development of follicles by interacting with WNT4. We acknowledge that our study design was not optimal because of the small sample size and a specific breed of animals. However, despite these limitations, our results have enhanced our understanding of the regulation of TLRs, WNT4 and FOXL2 in goat follicular selection.

\section{Conflicts of interest}

The authors declare no conflict of interest.

\section{ACKNOWLEDGMENTS}

Research supported by the Fundamental Research Funds for the Central Universities (\#XDJK2016B003 and \#SWU114052) and the 2013 Innovation Team-Building Program in Chongqing University (\#KJTD201334).

\section{REFERENCES}

Aflatoonian R and Fazeli A (2008). Toll-like receptors in female reproductive tract and their menstrual cycle dependent expression. J. Reprod. Immunol. 77: 7-13.http://dx.doi.org/10.1016/j.jri.2007.03.014

Aflatoonian R, Tuckerman E, Elliott SL, Bruce C, et al. (2007). Menstrual cycle-dependent changes of Toll-like receptors in endometrium. Hum. Reprod. 22: 586-593.http://dx.doi.org/10.1093/humrep/del388

Auguste A, Chassot AA, Grégoire EP, Renault L, et al. (2011). Loss of R-spondin1 and Foxl2 amplifies female-to-male sex reversal in XX mice. Sex Dev. 5: 304-317. http://dx.doi.org/10.1159/000334517

Bromfield JJ and Sheldon IM (2011). Lipopolysaccharide initiates inflammation in bovine granulosa cells via the TLR4 pathway and perturbs oocyte meiotic progression in vitro. Endocrinology 152: 5029-5040. http://dx.doi.org/10.1210/ en.2011-1124

Brubaker SW, Bonham KS, Zanoni I and Kagan JC (2015). Innate immune pattern recognition: a cell biological perspective. Annu. Rev. Immunol. 33: 257-290.http://dx.doi.org/10.1146/annurev-immunol-032414-112240

Boulanger L, Pannetier M, Gall L, Allais-Bonnet A, et al. (2014). FOXL2 is a female sex-determining gene in the goat. Curr. Biol. 24: 404-408.http://dx.doi.org/10.1016/j.cub.2013.12.039

Chen C, Zibiao H, Ming Z, Shiyi C, et al. (2014). Expression pattern of Toll-like receptors (TLRs) in different organs and effects of lipopolysaccharide on the expression of TLR 2 and 4 in reproductive organs of female rabbit. Dev. Comp. Immunol. 46: 341-348. http://dx.doi.org/10.1016/j.dci.2014.05.008

Georges A, Auguste A, Bessière L, Vanet A, et al. (2013). FOXL2: a central transcription factor of the ovary. J. Mol. Endocrinol. 52: R17-R33. http://dx.doi.org/10.1530/JME-13-0159

Gu BX, Wang X, Yin BL, Guo HB, et al. (2016). Abnormal expression of TLRs may play a role in lower embryo quality of women with polycystic ovary syndrome. Syst Biol Reprod Med 62: 353-358. http://dx.doi.org/10.1080/1939636 $\underline{8.2016 .1187683}$

Gustin SE, Hogg K, Stringer JM, Rastetter RH, et al. (2016). WNT/b-catenin and p27/FOXL2 differentially regulate supporting cell proliferation in the developing ovary. Dev. Biol. 412: 250-260. http://dx.doi.org/10.1016/j. ydbio.2016.02.024

Hirano M, Wada-Hiraike O, Fu H, Akino N, et al. (2016). The emerging role of FOXL2 in regulating the transcriptional activation function of estrogen receptor b: An insight into ovarian folliculogenesis. Reprod. Sci. [Epub ahead of print].

Hoshino K, Takeuchi O, Kawai T, Sanjo H, et al. (1999). Cutting edge: Toll-like receptor 4 (TLR4)-deficient mice are hyporesponsive to lipopolysaccharide: evidence for TLR4 as the Lps gene product. J. Immunol. 162: 3749-3752.

Jin H, Won M, Park SE, Lee S, et al. (2016). FOXL2 is an essential activator of SF-1-induced transcriptional regulation of anti-müllerian hormone in human granulosa cells. PLoS One 11: e0159112. http://dx.doi.org/10.1371/journal. pone. 0159112

Genetics and Molecular Research 15 (4): gmr15049157 
Leung DT, Fuller PJ and Chu S (2016). Impact of FOXL2 mutations on signaling in ovarian granulosa cell tumors. Int. J. Biochem. Cell Biol. 72: 51-54. http://dx.doi.org/10.1016/j.biocel.2016.01.003

Maatouk DM, Mork L, Chassot AA, Chaboissier MC, et al. (2013). Disruption of mitotic arrest precedes precocious differentiation and transdifferentiation of pregranulosa cells in the perinatal Wnt4 mutant ovary. Dev. Biol. 383: 295306. http://dx.doi.org/10.1016/j.ydbio.2013.08.026

Medan MS, Watanabe G, Sasaki K, Groome NP, et al. (2005). Follicular and hormonal dynamics during the estrous cycle in goats. J. Reprod. Dev. 51: 455-463. http://dx.doi.org/10.1262/jrd.17017

Meng XL, Liu P, Jia FL, Li J, et al. (2015). De novo transcriptome analysis of Portunus trituberculatus ovary and testis by RNA-Seq: Identification of genes involved in gonadal development. PLoS One 10: e0128659. http://dx.doi. org/10.1371/journal.pone.0128659

Naillat F, Yan W, Karjalainen R, Liakhovitskaia A, et al. (2015). Identification of the genes regulated by Wnt-4, a critical signal for commitment of the ovary. Exp. Cell Res. 332: 163-178. http://dx.doi.org/10.1016/j.yexcr.2015.01.010

Raja A, Vignesh AR, Mary BA, Tirumurugaan KG, et al. (2011). Sequence analysis of Toll-like receptor genes 1-10 of goat (Capra hircus). Vet. Immunol. Immunopathol. 140: 252-258. http://dx.doi.org/10.1016/j.vetimm.2011.01.007

Schmidt D, Ovitt CE, Anlag K, Fehsenfeld S, et al. (2004). The murine winged-helix transcription factor Fox12 is required for granulosa cell differentiation and ovary maintenance. Development 131: 933-942. http://dx.doi.org/10.1242/ dev.00969

Schmittgen TD and Livak KJ (2008). Analyzing real-time PCR data by the comparative $\mathrm{C}_{\mathrm{T}}$ ) method. Nat. Protoc. 3: 11011108. http://dx.doi.org/10.1038/nprot.2008.73

Shimada M, Yanai Y, Okazaki T, Noma N, et al. (2008). Hyaluronan fragments generated by sperm-secreted hyaluronidase stimulate cytokine/chemokine production via the TLR2 and TLR4 pathway in cumulus cells of ovulated COCs, which may enhance fertilization. Development 135: 2001-2011.http://dx.doi.org/10.1242/dev.020461

Sominsky L, Sobinoff AP, Jobling MS, Pye V, et al. (2013). Immune regulation of ovarian development: programming by neonatal immune challenge. Front. Neurosci. 7: 100. http://dx.doi.org/10.3389/fnins.2013.00100

Spanel-Borowski K (2011). Ovulation as danger signaling event of innate immunity. Mol. Cell. Endocrinol. 333: 1-7. http://dx.doi.org/10.1016/j.mce.2010.12.008

Taghavi SA, Ashrafi M, Mehdizadeh M, Karimian L, et al. (2014). Toll-like receptors expression in follicular cells of patients with poor ovarian response. Int. J. Fertil. Steril. 8: 183-192.

Tomizuka K, Horikoshi K, Kitada R, Sugawara Y, et al. (2008). R-spondin1 plays an essential role in ovarian development through positively regulating Wnt-4 signaling. Hum. Mol. Genet. 17: 1278-1291.http://dx.doi.org/10.1093/hmg/ddn036

Wu XQ, Wang YQ, Xu SM, Liu JF, et al. (2015). The WNT/b-catenin signaling pathway may be involved in granulosa cell apoptosis from patients with PCOS in North China. J. Gynecol. Obstet. Biol. Reprod. [Epub ahead of print].

Zandieh Z, Amjadi F, Ashrafi M, Aflatoonian A, et al. (2016). The effect of estradiol and progesterone on Toll-like receptor gene expression in a human fallopian tube epithelial cell line. Cell J. 17: 678-691.

Zhou M, McFarland-Mancini MM, Funk HM, Husseinzadeh N, et al. (2009). Toll-like receptor expression in normal ovary and ovarian tumors. Cancer Immunol. Immunother. 58: 1375-1385. http://dx.doi.org/10.1007/s00262-008-0650-y

Genetics and Molecular Research 15 (4): gmr15049157 